\title{
CONTRIBUIÇÃO DA FITOQUÍMICA PARA O DESENVOLVIMENTO DE UM PAÍS EMERGENTE\#
}

\author{
Raimundo Braz Filho
}

Universidade Federal Rural do Rio de Janeiro / Universidade Estadual do Norte Fluminense Darcy Ribeiro, 28013- 602

Campos dos Goytacazes - RJ, Brasil

Recebido em 2/6/09; publicado na web em 8/12/09

\begin{abstract}
PHYTOCHEMICAL CONTRIBUTION TO DEVELOPMENT OF A EMERGENT COUNTRY. The sustainable development of an emergent country is dependent on a consistent scientific, technologic and innovative policy, on nature and biodiversity, on a rational exploration of natural resources to feeding, social advance and economical aim along with maintenance of health and diseases treatment. Phytochemical investigations may be used to contribute with development throughout undergraduate and graduate career preparing professionals with qualification to these activities, as researcher and professor, including discovering and divulgation of new scientific knowlegments. The role of organic compounds produced by secondary metabolism of plants in the development of new drugs is presented (e. g.) throughout exposition using examples of features involved in this activity, since the recognition of a plant-derived popular medicine, until the laboratory semi-synthesis of its main constituents. Several aspects related to the use of some vegetable species in treatment of many tropical diseases are pointed. Economical and social importance of isolation, structural characterization, pharmacological investigation and chemical transformations of new natural organic substances isolated from the plants are related.
\end{abstract}

Keywords: emergent country; phytochemical investigations; structural identifications.

\section{INTRODUÇÃO}

O desenvolvimento sustentável de um país depende essencialmente de uma política consistente de educação, ciência, tecnologia e inovação, sustentada na preservação da natureza, na biodiversidade e na exploração racional de fontes naturais necessárias para alimentação, avanço social e econômico, num cenário que assegura a manutenção da saúde e a cura de doenças.

As atividades da fitoquímica podem contribuir significativamente para a concretização de tal programação através da investigação da flora e seu quimismo, da divulgação e geração de novos conhecimentos e da formação de recursos humanos qualificados. A química de produtos naturais (QPN) de vegetais - fitoquímica, como é concebida atualmente, se dedica principalmente à caracterização estrutural, avaliação de propriedades e investigações biossintéticas de substâncias naturais produzidas pelo metabolismo secundário de organismos vivos. ${ }^{1}$

A vida dos organismos vivos - nascimento, crescimento, reprodução, envelhecimento, doenças e morte - é assegurada e controlada pelas transformações químicas realizadas por metabolismos primário (principal atividade dos bioquímicos) e secundário - especializado (atividade primordial do químico de produtos naturais).

Assim, os organismos vivos utilizam trajetórias biogenéticas para transformações e interconversões químicas de metabólitos do seu acervo vivo e dinâmico (Esquema 1). As principais biorreações utilizadas em tais processos vitais envolvem reações de alquilação (substituição nucleofílica, adição eletrofílica), rearranjos de Wagner - Meerwein, condensação aldólica, reação de Claisen, formação da base de Schiff, reação de Mannich, transformações, carboxilações e descarboxilações, oxidações e reduções (Esquema 1). ${ }^{1,2}$ Neste esquema não aparecem as rotas biossintéticas não convencionais (envolvendo os três aminoácidos L-valina, L-isoleucina e L-leucina, o ciclo-hexanocarboxilato, o 3,4-dihidroxiciclo-hexanocarboxilato), exceto uma sumária sinalização da rota do isopreno independente do mevalonato.

"Conferência convidada, proferida na 32 ${ }^{\mathrm{a}} \mathrm{RASBQ}$, Fortaleza - CE, 2009. *e-mail: braz@uenf.br / Pesquisador Visitante Emérito, Fundação de Amparo à Pesquisa do Estado do Rio de Janeiro

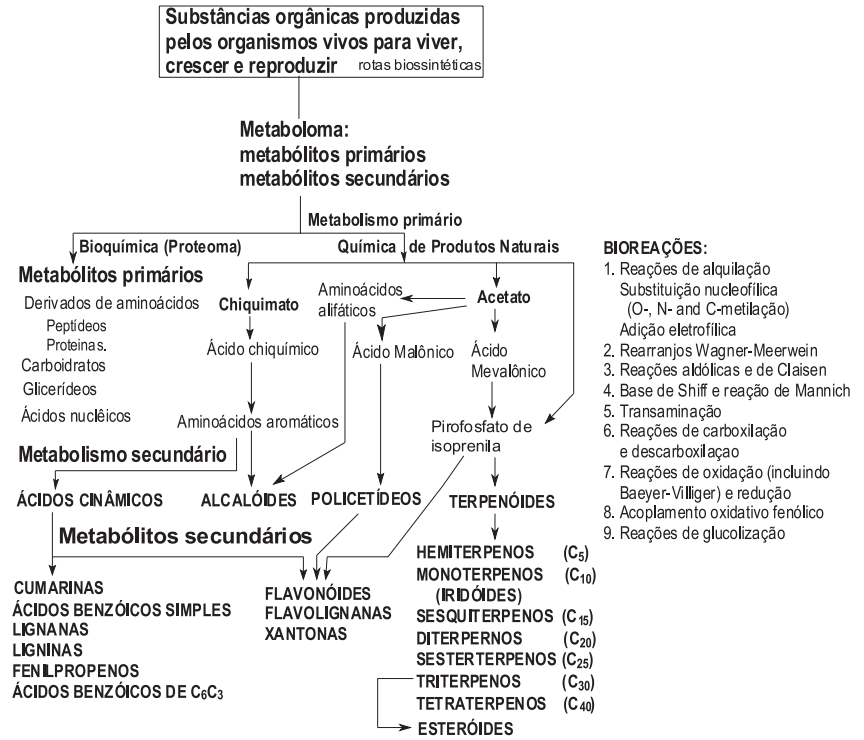

Esquema 1. Substâncias naturais produzidas pelo metabolismo primário e secundário e biorreações

Na função genômica dos organismos vivos, o fenótipo pode ser definido pelas características morfológicas, pelas medições fisiológicas e pelas análises bioquímica (proteômicas) e química (metabolômicas), envolvendo, consequentemente, a participação dos metabolismos primário e secundário (Esquema 1). A metabolômica é definida com a análise qualitativa e quantitativa de todos os metabólitos num organismo. Nos últimos anos verificou-se um esperado crescimento envolvendo a caracterização química de fenótipo. Tal caracterização química pode ser realizada através de análise de macromoléculas (e.g. proteômicas e caracterização de polissacarídeos e ligninas) e de moléculas (micromeléculas) de baixo peso molecular (o metaboloma). O metaboloma consiste de dois tipos de substâncias, os metabólitos primários e os secundários. O metabolismo primário fornece as substâncias envolvidas nas funções básicas essenciais 
da vida celular - respiração e biossíntese de aminoácidos e outras substâncias necessárias para a vida da célula. Basicamente, todos organismos convivem com os mesmos tipos de metabólitos primários e da incompetência para autoprodução de tais produtos, pela sua própria rota biossintética; surge a necessidade de providências para superar tal incapacidade orgânica pela busca de fornecimento usando fonte externa. Os metabólitos secundários são específicos das espécies e participam das interações intra- e intercelular do próprio organismo ou com células de outros organismos, atuam em processos de polinização pela produção de substâncias que atraem os agentes vivos deste processo ou contribuem para a resistência dos organismos pela defesa contra pestes e outras doenças e estabelecendo a competência para a guerra química dos ajustes necessários à convivência e sobrevivência ambiental. Assim, por exemplo, o metabolismo primário assume importância transcendental no crescimento e rendimento agrícola e o metabolismo secundário contribui com os aromas, as cores dos alimentos e com a resistência contra pestes e doenças, mantendo a sobrevivência nas condições ambientais favoráveis.

$\mathrm{O}$ crescente interesse interdisciplinar envolve também a participação efetiva da química de produtos naturais (Esquema 2), contribuindo para o desenvolvimento de outras áreas do conhecimento: biologia molecular, botânica ecológica, sistemática e evolutiva, farmacologia, biotecnologia, química orgânica (novos modelos para síntese, novas reações, novos reagentes, teste de reagentes), medicina (descoberta de novos medicamentos), agricultura (defensivos agrícolas) e veterinária (medicamentos para outros animais). A contribuição para as investigações metabolômicas (Esquema 2) pode ser avaliada claramente pela metodologia usada na plataforma metabolômica: métodos cromatográficos e espectrométricos, principalmente espectrometria de massas (EM) e ressonância magnética nuclear (RMN $1 \mathrm{D}$ e $2 \mathrm{D})$

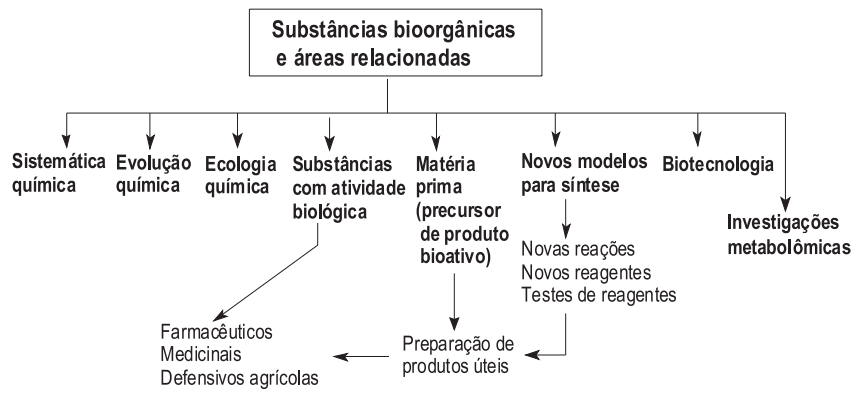

Esquema 2. Importância e interdisciplinaridade de substâncias bioorgânicas produzidas pelo metabolismo secundário

As plantas superiores constituem uma das fontes mais importantes de novas substâncias utilizadas diretamente como agentes medicinais. Mais recentemente, além disto, elas fornecem modelos para modificações estruturais e otimização das propriedades farmacológicas e bioquímicas, servindo, inclusive, para a inspiração de químicos orgânicos, estimulando-os para enfrentar desafios na construção sintética de novas arquiteturas moleculares naturais.

Durante algum tempo, os investimentos elevados na preparação de produtos sintéticos contribuíram significativamente para estimular ações que tentavam reduzir a relevância de organismos vivos como fontes de novos bioprodutos com atividade biológica. Nos últimos anos, no entanto, a importância dos organismos vegetais como fontes produtivas de substâncias anticancerígenas e outras atividades biológicas reativaram interesses sociais e econômicos, superando obstáculos na construção de cenário crescente, estimulando, inclusive, a percepção das lideranças industriais empenhadas na fabricação de produtos sintéticos.
Durante o período de 1960 a 1986, no programa de avaliação de substâncias antitumorais de origem vegetal do Instituto Nacional do Câncer dos Estados Unidos foram investigados 108.330 extratos obtidos de 35.000 espécies vegetais: 4.149 (3,83\%), correspondentes a 1410 gêneros envolvendo 2935 espécies, revelaram atividade biológica. Das 2.000 substâncias cristalinas isoladas e testadas, 95 (4,75\%) foram selecionadas para investigações especiais e 11 aprovadas para testes contra diversos tumores. Entre tais substâncias foram indicadas a brucetina (1), a maitansina (2), o colubrinol (3), a indicina-N-óxido (4), o tripdiolido (5), o taxol (6), a homo-harringtonina (7) e elipticina (8), além da bouvardina (um peptídio cíclico de fórmula molecular $\mathrm{C}_{40} \mathrm{H}_{48} \mathrm{~N}_{6} \mathrm{O}_{10}$ ). ${ }^{3}$
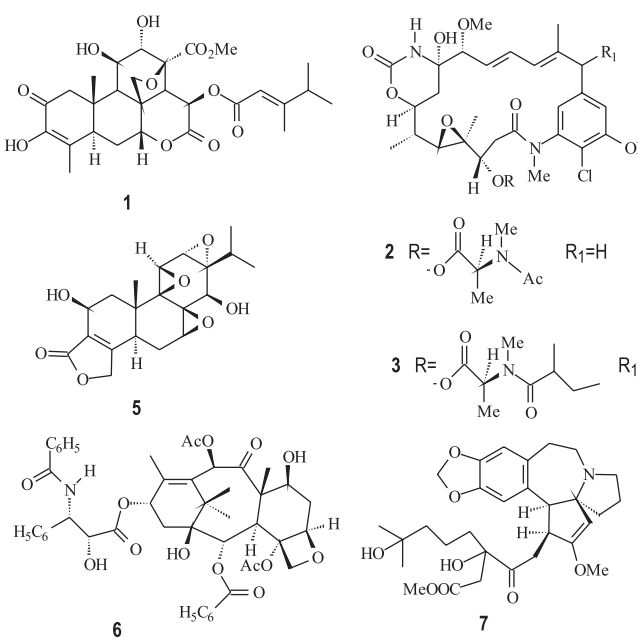

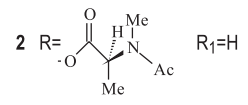
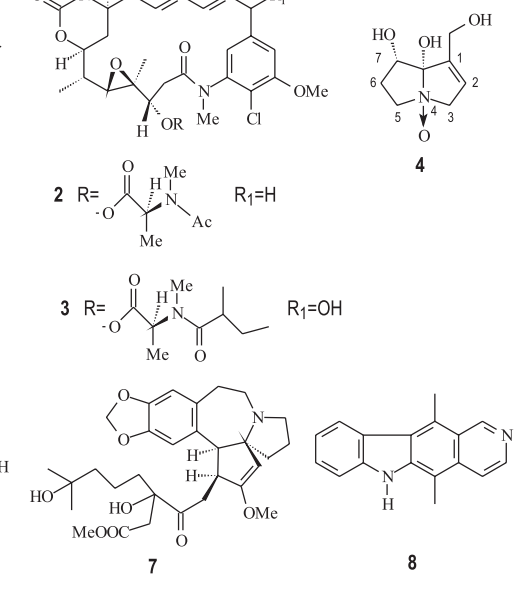

Os alcaloides vincristina (9) e vimblastina (10), isolados da espécie Catharanthus roseus, destacam-se como dois dos mais importantes agentes quimioterapêuticos de uso clínico corrente contra o câncer, seguidos pelos produtos semissintéticos etoposido (VP-26,11) e teniposido (VM-26,12), obtidos de epipodofilotoxina (13), um epímero do lignoide podofilotoxina (14) isolado das espécies Podophyllum peltatum e $P$. endoii. ${ }^{4}$

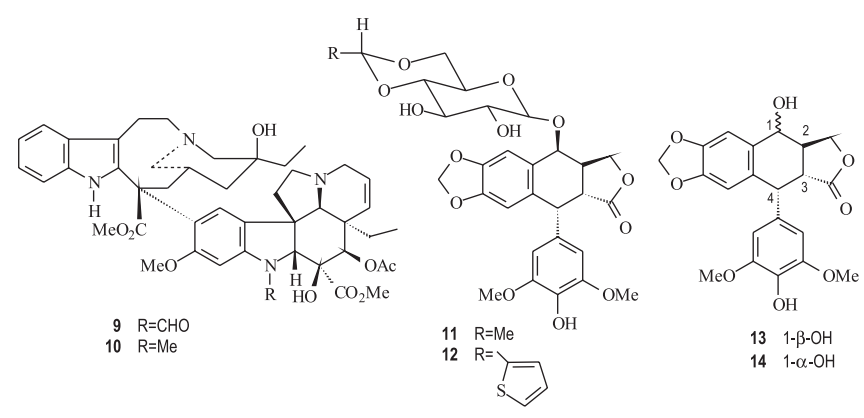

A medicina alopática mundial utiliza 119 drogas, todas com estruturas definidas, que são extraídas de cerca de 90 espécies de plantas superiores. ${ }^{5}$ Cerca de $25 \%$ de todas prescrições médicas nos Estados Unidos incluem substâncias naturais como princípio ativo, obtidas de plantas de regiões temperadas e tropicais, o que corresponde ao valor estimado de 900 milhões de dólares na circulação comercial. A utilização de diversas plantas na medicina popular representa uma investigação pré-clínica que não pode ser ignorada ou desprezada. Cerca de $74 \%$ dos principais produtos medicinais obtidos de vegetais foram descobertos através de orientação baseada em resultados revelados pela medicina popular. ${ }^{6}$ 
Dispomos, portanto, de um esplêndido acervo natural de vegetais nos ambientes aquáticos e terrestres; um potencial químico adormecido, de pujança inteiramente desproporcional ao esforço relativamente pequeno das pesquisas desenvolvidas para seu conhecimento e utilização.

A relativa facilidade de coleta, a condição ambiental favorável para desenvolvimento sustentável, a biodiversidade estrutural de substâncias orgânicas naturais e a possibilidade de descoberta de princípios ativos entre tais constituintes químicos permitem diagnosticar e destacar as plantas brasileiras como a principal fonte renovável para o surgimento e desenvolvimento de novos fármacos, além de outros produtos que podem ser utilizados para finalidades sociais adicionais. Diversas plantas tropicais têm utilização na medicina popular caseira e encontram-se documentadas por dados etnobotânicos.

A biodiversidade das florestas tropicais serve também como foco para a descoberta de novas plantas medicinais. A interação entre plantas tropicais e seus predadores naturais pode ser usada como suporte para a descoberta de substâncias ativas e, como consequência, orientar as investigações farmacológicas. A dinâmica ambiental envolvendo interações planta-planta, planta-animal e animal-animal depende essencialmente de uma convivência controlada pelo quimismo de diversos organismos vivos. O quimismo dos organismos vivos depende da força metabólica geral e a química do metabolismo secundário assume importância especial (metabolismo especializado) pela bioprodução de diversas substâncias orgânicas destinadas à manutenção e sobrevivência humana, assumindo também importância fundamental na guerra química que é mantida na vida dos meios ambientes naturais e artificiais produzidos pela atuação dos seres humanos.

Assim, o isolamento e a determinação estrutural de substâncias orgânicas produzidas pelo metabolismo secundário de organismos vivos representam importância fundamental para o desenvolvimento científico da própria química de produtos naturais e contribuem para avanço de outras atividades científicas e tecnológicas no País. A diversidade estrutural de substâncias orgânicas naturais isoladas de plantas da flora brasileira, o potencial relevante deste arsenal químico para o desenvolvimento social e econômico e a correspondente contribuição da química de produtos naturais para o avanço científico e tecnológico recebeu atenção especial de pesquisadores envolvidos em tais pesquisas no território nacional. ${ }^{7-11}$

A análise do número e fontes de agentes para combater câncer e doenças infecciosas, registrados principalmente em Annual Reports of Medicinal Chemistry durante o período de 1984 a 1995, indicou que mais de $60 \%$ das drogas aprovadas e pré-candidatas no NDA (período 1989 a 1995) são de origem natural. Drogas de origem natural aparecem classificadas como produtos naturais originais, derivados semissintéticos de produtos naturais e produtos sintéticos baseados em produtos naturais como modelos. ${ }^{12}$

Após seis anos da publicação acima mencionada, os autores constataram que as fontes de novas drogas de origem natural para tratamento de doenças humanas cancerígenas e infecciosas destacamse, respectivamente, com 60 e $75 \% .^{13}$

Estimativa anual da Organização Mundial da Saúde revela que mais de 270 milhões de pessoas tomam-se vitimas de malária, causando a morte de 2 a 3 milhões delas (cerca de um milhão são crianças). A resistência adquirida pelo Plasmodium falciparum contra medicamentos antimaláricos de amplo uso, como a cloroquina (vide infra), requer a descoberta de novos fármacos eficientes, preferencialmente sem efeitos colaterais indesejáveis.

Estima-se a existência de 250.000 espécies de plantas superiores. Cerca de $80 \%$ da população dos países subdesenvolvidos e em desenvolvimento continuam completamente dependentes da medicina caseira utilizando vegetais para as necessidades primárias de saúde.
Tabela 1. Dados do Ministério da Saúde do Brasil, referentes a 1993, sobre doenças que afetam drasticamente a população brasileira

\begin{tabular}{ll}
\hline Doenças & Vitimas \\
\hline Malária & 530.000 \\
Esquistossomose & 5.000 .000 \\
Doença de Chagas & 5.000 .000 \\
Hanseniase & 200.000 \\
Tuberculose & 100.000 \\
Cólera & 39.000 \\
Aids & 52.000 \\
Desnutrição & 32.000 .000 \\
\hline
\end{tabular}

*Banco Mundial: Brasil aparece em penúltimo lugar na distribuição de renda. **Levantamento do Conselho de Segurança Alimentar.

Tem sido estimado que somente de 5-15\% destas espécies foram investigadas, restando uma fonte natural de inúmeros organismos vivos contendo significativo número de substâncias inéditas e forte potencial de produtos naturais bioativos, incluindo-se fontes de matérias-primas para o desenvolvimento de novos fármacos.

As atividades desenvolvidas pela química de produtos naturais promovem o processo de formação de recursos qualificados, de importância fundamental, para os países emergentes. A Tabela 2 revela relação entre 1000 habitantes e o número de doutores em países desenvolvidos e escolhidos como referência. Os dados resumidos demonstram, inclusive, a carência relativa existente no nosso País.

Tabela 2. Relação do número de Doutores para cada 1000 habitantes

\begin{tabular}{lc}
\hline País & Número de Doutores/1000 habitantes \\
\hline Alemanha & 35 \\
Reino Unido & 20 \\
Japão & 14 \\
Coréia & 06 \\
Brasil & 0,6 \\
\hline
\end{tabular}

Atualmente, o Brasil conta somente com cerca de 107.000 pesquisadores Doutores, 170.000 Mestres e 80.000 estudantes de pós-graduação.

Livro, lançado recentemente, destina-se também aos jovens estudantes envolvidos em processos de formação acadêmica, principalmente alunos de graduação dedicados a trabalhos de iniciação científica (IC) e de pós-graduação (Mestrado e Doutorado). ${ }^{14}$ Esta obra procura demonstrar com clareza a importância da química de produtos naturais e as áreas correlacionadas, despertando e estimulando o interesse interdisciplinar.

Para concluir esta sumária introdução, destaco os benefícios químicos do agradável produto de origem vegetal, tradicionalmente conhecido como chocolate (combustível humano), produzido das sementes do cacau, espécie Theobrama Cacao Lin.(família Malvaceaae), que fornece fenilalanina (15) como precursor para a bioprodução da serotonina (16), substância importante para combater a depressão e a ansiedade (Esquema 3). Outras substâncias também importantes (estimulantes) são as famosas teobromina (17) e a cafeína (18), Esquema 3, além de flavonoide antioxidante.

Aproximadamente 25\% das prescrições médicas nos Estados Unidos incluem substâncias naturais como princípio ativo, obtidas de plantas de regiões temperadas e tropicais, o que corresponde ao valor estimado de 900 milhões de dólares na circulação comercial. 
Theobroma Cacao Lin. (cacau): sementes utilizadas para produção de chocolate Família Malvaceae

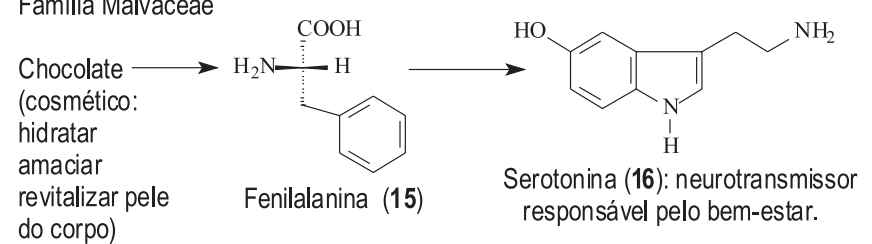

do corpo)

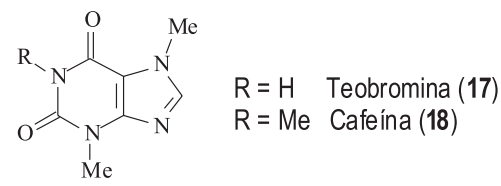

Esquema 3.

A utilização de diversas plantas na medicina popular representa uma investigação pré-clínica que não pode ser ignorada ou desprezada.

\section{SUBSTÂNCIAS ORGÂNICAS NATURAIS E SEMISSINTÉTICAS ANTIMALÁRIA}

O Brasil convive com 530.000 vítimas de malária (Tabela 1), doença provocada por protozoários de gênero Plasmodium, ( $P$. Vivax, $P$. malariae, $P$. ovale e P. falciparum) que invadem o sistema circulatório das glândulas salivares das fêmeas infestadas dos mosquitos Anopheles.

Estimativa anual da Organização Mundial da Saúde (OMS) revela que mais de 270 milhões de pessoas tomam-se vitimas de malária, causando a morte de 2 a 3 milhões delas (cerca de um milhão são crianças).

Dois antimaláricos naturais, quinina (19) e artemisinina (20), podem ser utilizados como exemplos marcantes numa demonstração clara do enorme potencial de produtos naturais como fontes de fármacos e de matéria-prima para produção de substâncias também ativas semissintéticas $(19 \mathrm{a}=$ cloroquinina, $19 \mathrm{~b}=$ primaquina e $19 \mathrm{c}=$ mefloquina; $\mathbf{2 0} \mathbf{a}=$ artemether, $\mathbf{2 0 b}=$ arteether, $\mathbf{2 0} \mathbf{c}=$ artesunato de sódio), na busca de maior atividade e eliminação ou redução de efeitos nocivos.

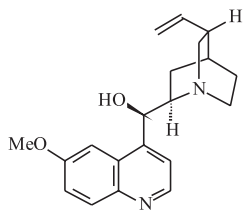

19 (quinina)

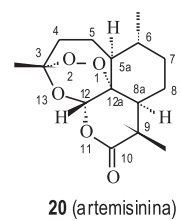

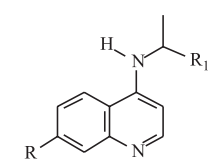

19a R $=\mathrm{Cl}, \quad \mathrm{R}_{1}=\mathrm{CH}_{2} \mathrm{CH}_{2} \mathrm{CH}_{2} \mathrm{NEt}_{2}$ (cloroquinina)

$19 \mathrm{~b} R=\mathrm{OMe}, \mathrm{R}_{1}=\mathrm{CH}_{2} \mathrm{CH}_{2} \mathrm{CH}_{2} \mathrm{NEt}_{2}$ (primaquina)

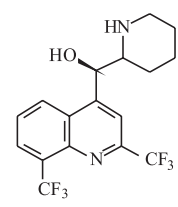

19c (mefloquina)

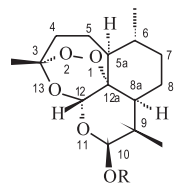

20a $\mathrm{R}=\mathrm{Me}$ (artemether)

20b R $=\mathrm{Et}$ (arteether)

$20 \mathrm{c} \mathrm{R}=\mathrm{CH}_{2} \mathrm{CH}_{2} \mathrm{CO}_{2} \mathrm{Na}$

(artesunato de sódio)

A resistência adquirida pelo Plasmodium falciparum contra medicamentos antimaláricos de amplo uso, como a cloroquina (19a), requer a descoberta de novos fármacos eficientes, preferencialmente sem efeitos colaterais indesejáveis.

Na década de 70 surgiu um potente agente antimalárico natural (20), isolado de ArtemIsia annua (família Asteraceae), essencialmente sem toxidez. Os resultados obtidos com esta substância natural na República Popular da China, a preparação de derivados mais potentes e os 16 séculos de uso popular de Artemisia annua e A. Apiacea, para tratamento de malária, por indicação da Encic!opédia de Matéria Médica daquele país, continuam servindo como estímulo adicional para promover a retomada desses fatos históricos marcantes. ${ }^{7}$

O gênero Artemisia engloba cerca de 300 espécies, sendo que a investigação de outras 100 espécies (30 por pesquisadores chineses e 70 por pesquisadores americanos) revelou a ausência de artemisinina (20), exceto numa variedade japonesa de Artemisia apiacea (rendimento de $0,0008 \%$ ) e na A. lancea.

$\mathrm{O}$ interesse despertado pela importância medicinal da artemisinina (20) como antimalárico estimulou intensa investigação na busca de outros constituintes de Artemisia annua e de outras espécies do mesmo gênero (Artemisia). Na A annua o bioconstituinte mais abundante é o ácido artemisínico (ácido arteanúico, 21), com rendimento 8 a 10 vezes maior que artemisinina (20). Além disto, a planta produz outros sesquiterpenoides. A quantidade isolada de ácido artemisínico permitiu sua utilização como substrato para obtenção de derivados sesquiterpenoides: artemisiteno (22, isolado da planta em baixo rendimento e com menor atividade antimalária do que a artemisinina), artemisinina (20), desoxiartemisina, desoxiartemisinina, homodesoxoartemisinina e artenuína B. ${ }^{16}$

Além dos terpenoides citados e dos componentes do óleo essencial, foram isolados de A. annua dois alcoóis alifáticos, cumarinoides, flavonoides, fenóis, ésteres, um alcaloide e $\beta$-glicosidases, demonstrando a potencialidade química da planta. O componente principal $(35,7 \%)$ do óleo essencial é a 3,3,6-trimetil-1,5-heptadien-4-ona (23). ${ }^{16}$
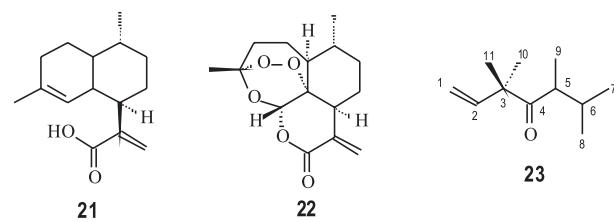

Principalmente na República Popular da China e nos Estados Unidos, foram preparados cerca de 100 derivados semissintéticos da artemisinina (20), todos mantendo a função endoperóxido, que é essencial para a atividade antimalárica. Vários derivados lactóis revelaram-se mais ativos do que a artemisina: carbonatos>ésteres $>$ artemisina. ${ }^{16}$

Na década de 60, os chineses retomaram a investigação de várias ervas utilizadas na medicina tradicional do país. O chá quente obtido de Artemisia annua, conhecida popularmente como "ging hao", desapontou os investigadores pela ausência de atividade biológica. Para a obtenção do produto ativo artemisinina (20, conhecida, também, como artenuína e pelos chineses como "ginhaousu" = extrato da planta "ging hao"), a extração do material foi feita com éter etílico (ou éter de petróleo, p. e. $=30-60^{\circ} \mathrm{C}$ ) em baixa temperatura. Após a elucidação estrutural foi possível compreender a necessidade de extração a baixa temperatura, para evitar a modificação térmica da estrutura, envolvendo, principalmente, a função peróxido localizada entre os átomos de carbono 3 e 12a (20). A função peróxido é essencial para o desempenho biológico antimalárico da substância natural (20). ${ }^{16}$

A inviabilidade econômica revelada pela avaliação dos vários trabalhos descritos na literatura, ${ }^{17}$ a impossibilidade de cultivo de Artemisia annua em regiões tropicais e subtropicais (planta adaptada a zonas temperadas), e a riqueza e diversidade de nossa flora, além das informações sobre antimaláricos de uso popular na Amazônia, ${ }^{18}$ devem estimular, adicionalmente, a investigação de outras fontes naturais para descobrir novos antimaláricos.

A publicação de Brandão, Carvalho e Kretti ${ }^{18}$ descreve 42 espécies vegetais (distribuídas em 23 famílias), selecionadas após ouvir informações de 4689 habitantes de regiões do Pará e 750 de Rondônia. Cinco espécies aparecem com porcentagem de citação maior do que 5\%: Geissospennum sericeum Benth. (12,0\%, Apocynaceae), Momordica charantia L. (8,5\%, Cucurbitaceae), 
Bertelethia excelsa Humb. \& Bonpl. (8,8\%, Lecytidaceae), Senna occidentalis (L.) H. Irving \& Barbany (20,0\% LeguminosaeCaesalpinoidae) e Bowdichia sp (5,9\%, Leguminosae-Faboideae) Uma espécie de Artemisia (Artemisia sp, família Compositae) alcançou somente $1,1 \%$, o que é curioso mas não surpreendente, já que o quimismo exigido para a sobrevivência ambiental deste vegetal na região amazônica pode ser diferente daquele definido pela região temperada.

As investigações com extratos aquosos brutos de nove espécies revelaram somente dois com atividade em camundongos infectados com o Plasmodium beghei. ${ }^{18}$ Parece óbvio, após os trabalhos realizados com a Artemisia annua, ${ }^{16}$ que novas investigações com esta e outras espécies vegetais, avaliando-se os extratos obtidos com solventes orgânicos em temperatura adequada.

As substâncias antimaláricas isoladas de plantas e organismos marinhos pertencem a diversas classes de produtos naturais, tais como, alcaloides, terpenoides, quassinoides, flavonoides, xantoides, quinonoides, cumarinoides..$^{19,20}$

A medicina popular chinesa tem usado a mistura dos alcaloides febrifugina (24) e isofebrifugina (25), originalmente isolados de raízes de Dichroa febrífuga e extraídos também das folhas e bulbos de Hydrangea macrophylla var. Otaksa, há mais de 4000 anos, para tratmento de malária (Esquema 4). ${ }^{19}$

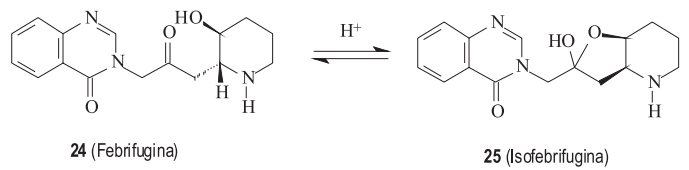

Esquema 4. Conversão de febrifugina (24) em isofebrifugina (25) em meio ácido

A notável conversão biocatalítica da 8-hidroximanzamina A (8OHMA, 26) em manzamina A (27) pelos fungos Fusarium solani e Streptomyces seokies merece destaque (Esquema 5). ${ }^{19}$ Esta biotransformação catalítica envolve a eliminação seletiva da hidroxila localizada no átomo de carbono C-8, fornecendo 27 como produto com muito maior atividade antimalárica.

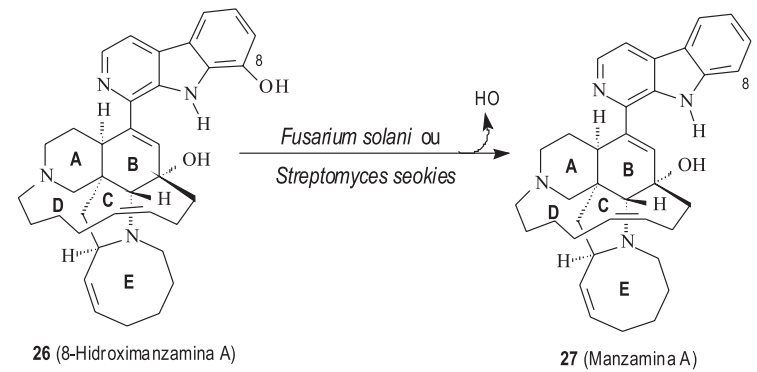

Esquema 5. Conversão biocataítica 8-hidroximanzamina A (8-OHMA, 26) em manzamina $A$ (27)

A classe das substâncias naturais conhecidas como quassinoides, comuns em espécies da família Simaroubaceae, envolve mais de 150 compostos orgânicos, incluindo-se os que se destacam como componentes de grupo que ocupa ampla faixa de atividades biológicas, tais como, anticancerígenos, antimaláricos, antiviral, anti-inflamatórios, inseticidas, amebicidas, antiúlceras, herbicidas. Temos contribuído significativamente para esta classe de produtos naturais, através da caracterização de substâncias inéditas (e.g. 28 e 29, isolados de Simaba cuneato, e $\mathbf{3 0}$ isolado de Simaba subcy$m o s a)^{21,22}$ e publicação de capítulo de livro impresso e lançado no exterior, ${ }^{10}$ além da expressiva contribuição para formação de recursos humanos qualificados.
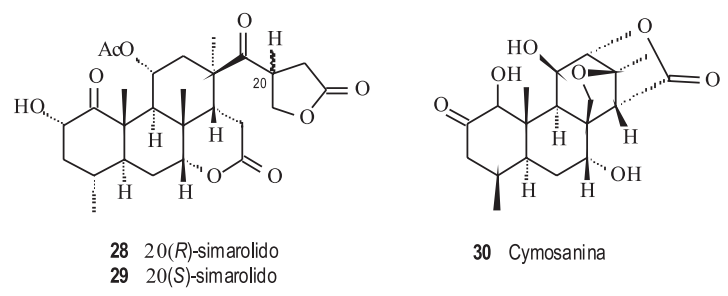

30 Cymosanina

A malária continua se destacando como uma das mais expressivas doenças infecciosas, matando mais 1 milhão de pessoas anualmente no mundo, deixando contagiados mais de 500 milhões. Tal cenário justifica a existência no Chemical Abstract (SciFinder Scholar) de 4.094 referências envolvendo artemisinina (20).

\section{SUBSTÂNCIAS ORGÂNICAS NATURAIS ANTIESQUISTOSSOMOSE}

A esquistossomose afeta a vida de 5 milhões de brasileiros (Tabela 1). Trata-se de uma doença endêmica do $3^{\circ}$ mundo, que atinge mais de 250 milhões de pessoas distribuídas em 76 países, alcançando principalmente as populações rurais..$^{23}$ Uma das vias de controle desta doença tropical envolve o combate de veículos transmissores. Destacam-se como principais agentes na disseminação da doença nos seres humanos: Schistasoma haematobium, S. mansoni e S. japonica.

Atualmente, a 2,5' -dicloro-4' -nitrosa1 icylamilida (niclosamida, 31, conhecida como bayluscida) é o único produto recomendado pela Organização Mundial da Saúde, porém seu preço inviabiliza o uso rotineiro nos países pobres.

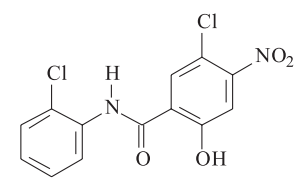

31

A toxicidade das drogas sintéticas disponíveis no mercado, a resistência adquirida pelos veículos transmissores, a poluição ambiental decorrente do combate aos transmissores e a disponibilidade de plantas com atividade moluscicida exigem uma ação coordenada efetiva e consistente para a investigação de plantas locais (onde ocorra a doença e existam veículos transmissores). A potente atividade revelada pelas saponinas naturais isoladas de Phytolacca dodecandra, família Phytolaccaceae despertou o interesse para a investigação de plantas visando também o controle e o combate da esquistossomose e seus veículos transmissores.

A literatura ${ }^{23}$ registrou critérios para definir plantas eficientes com possibilidades para revelar atividade moluscicida, destacandose principalmente:

a) alta atividade moluscicida. Os extratos brutos de onde poderão ser isolados componentes ativos devem revelar atividade em concentração menor do que $100 \mathrm{mg} / \mathrm{L}$, já que a ação do moluscicida sintético bayluscida (31) revelou atividade de $1 \mathrm{mg} /\left(\mathrm{LC}_{100}=0,3 \mathrm{mg} / \mathrm{L}\right.$ (após $24 \mathrm{~h}$ de tratamento) contra o transmissor Biomphalaria glabrata;

b) as plantas responsáveis pela atividade devem crescer, nativas ou cultivadas, facilmente no local onde ocorre a endemia, utilizando-se para extração preferencialmente flores, frutos ou folhas, evitando a destruição do organismo vegetal;

c) extração dos constituintes com água, o que torna o processo de isolamento barato. Esta orientação baseou-se na solubilidade das saponinas (glicosídeos) em água.

As saponinas triterpênicas isoladas dos frutos de Phytolacca dodecandra foram estudadas intensamente e revelaram alta ativi- 
dade moluscicida, assumindo condições favoráveis e promissoras para eficiente utilização. Outras plantas demonstraram também atividade moluscicida: Ambrosia maritima (família Asteraceae) no Egito, Acacia milotica (família Leguminosae) no Sudão, Anarcadium occidentale (família Anarcadiaceae) em Moçambique, Swartzia madagascariensis (família Leguminosae) e Tetrapleura tetraptera (família Leguminosae-Mimosoideae) na África e Sapindus rarak (família Sapindaceae) na Ásia.

O isolamento e a elucidação estrutural dos constituintes de extratos tornaram-se essenciais para estudos adicionais sobre toxicidade, estabilidade nas condições de uso, dosagem, estudos de estrutura-atividade, tipos eficientes de metabolito úteis e efeitos fisiológicos e genéticos.

A atividade moluscicida dos glicosídeos triterpenoides (saponinas) depende da natureza, da sequência e das ligações irterglicosídicas dos carboidratos que constituem a unidade carboidrática e da presença de substituintes na unidade aglicona triterpênica. Os diglicosídeos revelaram-se mais ativos do que os mono- e triglicosídeos.

Para citar como exemplo glicosídeos contendo o esqueleto básico oleanônico 32 como aglicona, selecionaram-se saponinas (33-36) isoladas de Sapindus rarak ${ }^{23}$ como referência para análise comparativa com o glicosídeo 37 isolado de Sapindus saponaria, através de trabalho desenvolvido na Universidade Federal do Ceará. ${ }^{24}$

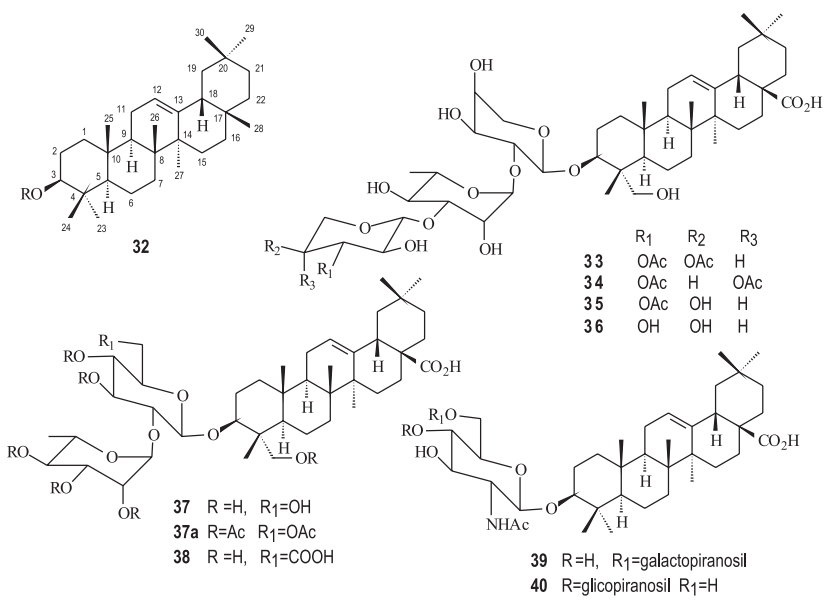

A atividade moluscicida revelada pelo extrato metanólico do pericarpo de Sapindus rarak (família Sapindaceae) foi usada para monitorar a investigação química. As quatro saponinas triterpênicas isoladas desse extrato, por métodos cromatográficos, foram caracterizadas como 33-36 através de dados espectrométricos.

Ensaios farmacológicos realizados com estas substâncias naturais isoladas revelaram as saponinas $\mathbf{3 3}, \mathbf{3 4}$ e $\mathbf{3 6}$ com maior atividade $\left(\mathrm{LC}_{100} / 24 \mathrm{~h}=6,25 \mathrm{mg} / \mathrm{L}\right)$ do que $35\left(\mathrm{LC}_{100}=12,5 \mathrm{mg} / \mathrm{L}\right)$, sendo as atividades das quatro menores do que as reveladas por outras saponinas naturais conhecidas. ${ }^{23}$

O triterpeno glicosídico 37, isolado do extrato etanólico da casca dos frutos de Sapindus saponaria, como derivado acetilado (37a) contém a mesma unidade aglicônica de 33-36 e a unidade carboidrato análoga à presente em 38, saponina mais ativa $\left(\mathrm{LC}_{100} / 24 \mathrm{~h}=\right.$ $3 \mathrm{mg} / \mathrm{L}$ ) contra os transmissores Bulinus glabosus e Biomphalaria glabrata e destacada entre aquelas isoladas de frutos de Swartzia madagascariensis (família Leguminosae). Esta comparação estrutural permite cogitar da atividade moluscicida da saponina 37 . O derivado peracetilado 37a revelou ação antimicrobiana (medida em mm de inibição) em testes realizados contra Pseudomonas aeruginosa ( $8 \mathrm{~mm}$; estreptomicina: $6 \mathrm{~mm})$, Bacillus subtilis $(9$ $\mathrm{mm}$; estreptomicina: $11 \mathrm{~mm}$ ) e Criptococus neaformans $(7 \mathrm{~mm}$; anfotericina: $9 \mathrm{~mm}){ }^{24}$
Atualmente se faz sentir a necessidade de esforço adicional para reinvestigação de Sapindus saponaria, especialmente os frutos, como fonte renovável de material. A probabilidade de se encontrar uma planta com atividade moluscicida nas áreas endêmicas é muito baixa e, por isto, as oportunidades que aparecem não podem ser desprezadas ou abandonadas.

Os diglicosídeos triterpênicos 39 e 40, isolados de frutos de Tetrapleura tetraptera Taub. (Família Legiminosae-Mimnosoideae), foram classificados entre os mais poderosos moluscicidas naturais, com atividade semelhante à das saponinas triterpênicas produzidas por Phytolacca dodecandra (família Phytolaccaceae). ${ }^{23}$ A presença do grupo NHAc não é essencial porque as saponinas de $P$. dodecandra não contêm este grupamento. ${ }^{25}$

Triterpenos naturais revelaram outras atividades biológicas, tais como, efeitos contra câncer (grupos lupano, ursano, oleanona, damarano, eufano), anti-inflamatórios, antimicrobianos, antiplasmódicos, antiulcerogênicos anticariogênicos, antiviral, anti-HIV, hepatoprotetores, cardioprotetores e analgésicos. ${ }^{26,27}$

Mais da metade das saponinas triterpênicas aparece surpreendentemente como glicosídeos de ácido oleanólico (41) e seus derivados, frequentemente sustentando unidade carboidrática como função éter no átomo de carbono $\mathrm{CH}-3$ e éster no carbono C-28. Tais circunstâncias estruturais justificam o surgimento de diversos artigos dedicados à síntese, intensificando-se o interesse pela produção de maior quantidade de substâncias naturais por via sintética para permitir as investigações de atividades biológicas sem as restrições impostas pelas pequenas quantidades isoladas dos organismos vivos. Pesquisadores chineses destacam-se nas investigações de métodos sintéticos mais eficientes. ${ }^{28,29}$

Cheng e colaboradores ${ }^{28}$ sintetizaram quinze saponinas do ácido oleanólico (41): cinco 3-monossacarídeos (42 - 46) três 28-monossacarídeos (47 - 49)], dois 3-dissacarídeos (50 - 51), dois 28-dissacarídeos (52 - 53), três 3-monossacarídeos-28-monossacarídeos (54 - 56) e um 3-monossacarídeo-28-dissacarídeos (57). Somente duas reações revelaram rendimento total abaixo de $50 \%$ (28 e 44\%), tendo as demais alcançado resultados entre 54 e $79 \%{ }^{28}$

Dezessete extratos alcaloidais de folhas, frutos, raízes e outras partes aéreas de sete espécies do gênero Solanum, ( $S$. agrarium, $S$. jabrense, S. melissarum, S. megalanys, S. paludosum, S. paraibanum e S. stipulaceum), família Solanaceae, encontradas no nordeste brasileiro, foram testados para avaliar a atividade moluscicida, através de aplicações em Biomphalaria glabrata, o hospedeiro intermediário de Schistosoma mansoni. Seis dos dezessete extratos testados revelaram atividade, sendo que duas espécies (S. jabrense e S. stipulaceum) forneceram resultados efetivos para sugerir a utilização no controle de esquistossomose. ${ }^{30}$ A solavetivona (58) e a solasodina (59) foram isoladas de $S$. jabrense..$^{31,32} \mathrm{Um}$ alcaloide esteroidal isolado de Solanum criticum foi recentemente caracterizado como 20-episolasodina (59a).

\section{SUBSTÂNCIAS ORGÂNICAS NATURAIS ANTIDENGUE}

Pesquisadores do Instituto de Farmacognosia e Fitoquímica da Universidade de Lausanne, Suíça, investigaram 386 extratos de plantas para avaliar a atividade contra o Aedes aegypti, mosquito responsável pela dengue hemorrágica que ocorre na Ásia, África e Américas. ${ }^{23} \mathrm{O}$ extrato diclorometânico de Artemisia borealis (família Asteraceae), uma das 46 (12\%) plantas que revelaram atividade contra $A$. aegipti, forneceu os policetídeos acetilênicos 60 e 61, que demonstraram forte atividade, porém, a estabilidade relativamente baixa destas substâncias naturais aparece como característica desfavorável para a implementação de uso prático. ${ }^{23}$ 


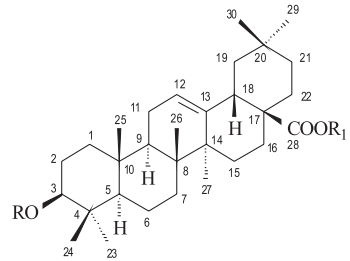

$41 \mathrm{R}=\mathrm{R}_{1}=\mathrm{H}$

$42 \mathrm{R}=\beta$-D-glicopiranosil, $\mathrm{R}_{1}=\mathrm{H}$

$43 \mathrm{R}=\beta$-D-galactopiranosil, $\mathrm{R}_{1}=\mathrm{H}$

$44 \mathrm{R}=\beta$-D-xilopiranosil, $\mathrm{R}_{1}=\mathrm{H}$

$45 \mathrm{R}=\alpha$-L-arabinopiranosil, $\mathrm{R}_{1}=\mathrm{H}$

$46 \mathrm{R}=\alpha$-L-ramnopiranosil, $\mathrm{R}_{1}=\mathrm{H}$

$47 \mathrm{R}=\mathrm{H}, \mathrm{R}_{1}=\beta$-D-galactopiranosil

$48 \mathrm{R}=\mathrm{H}, \mathrm{R}_{1}=\beta$-D-xilopiranosil

$49 \mathrm{R}=\mathrm{H}, \mathrm{R}_{1}=\alpha$-L-ramnopiranosil

$50 \mathrm{R}=\beta$-D-galactopiranosil-(1? 4)- $\beta$-D-glicopiranosil, $\mathrm{R}_{1}=\mathrm{H}$

$51 \mathrm{R}=\alpha$-D-glicopiranosil-(1? 4)- $\beta$-D-glicopiranosil, $\mathrm{R}_{1}=\mathrm{H}$

$52 \mathrm{R}=\mathrm{H}, \mathrm{R}_{1}=\beta$-D-galactopiranosil-(1? 4)- $\beta$-D-xilopiranosil

$53 \mathrm{R}=\mathrm{H}, \mathrm{R}_{1}=\alpha$-D-glicopiranosil-(1? 4)- $\beta$-D-glicopiranosil)

$54 \mathrm{R}=\beta$-D-galactopiranosil, $\mathrm{R}_{1}=\beta$-D-glicopiranosil

$55 R=\alpha$-L-arabinopiranosil, $R_{1}=\beta$-D-glicopiranosil

$56 \mathrm{R}=\beta$-D-galactopiranosiL, $\mathrm{R}_{1}=\beta$ - $\mathrm{D}$-xilopiranosil

$57 \mathrm{R}=\beta$-D-xilopiranosil, $\mathrm{R}_{1}=\alpha$-D-glicopiranosil-(1? 4)- $\beta$-D-glicopiranosi

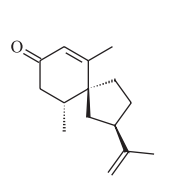

58
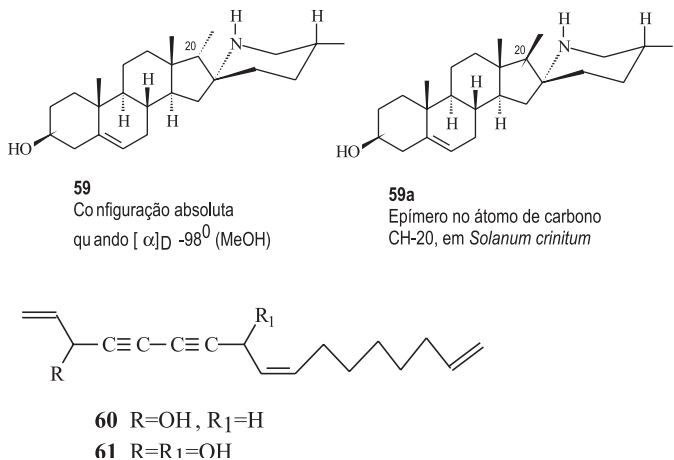

As saponinas oleanólicas isoladas de Pentaclethra macroloba (62 - 65), família Fabaceae, e de Cordia piauhiensis (66), família Boraginaceae, foram investigadas para se avaliar a atividade biológica contra Aedes aegypti, ${ }^{33}$ mosquito responsável pela dengue hemorrágica (vide infra).

O resultado experimental da avaliação da atividade larvicida das saponinas triterpênicas glicolisadas 62 - 66 revelou a substância natural 62, isolada das sementes de Pentaclethra macroloba, como mais ativa. Este resultado confirmou a atividade inseticida atribuída às sementes desta planta. ${ }^{33,34}$ Com base nos resultados experimentais obtidos, pode-se sugerir as substâncias naturais 62, 63 e 64 como promissoras agentes larvicidas. Curiosamente, a atividade larvicida passa por redução com o aumento do número de unidades carboidráticas ${ }^{33}$

Triterpenoides surgiram também como agente anti-HIV (vide infra) e, recentemente, as saponinas triterpênicas isoladas de Ampelozizyphus amazonicus, planta usada na medicina popular brasileira, revelaram efeito diurético em ratos. ${ }^{35}$

\section{SUBSTÂNCIAS ORGÂNICAS NATURAIS ANTI-HIV}

Os triterpenoides lupânicos 67 (ácido betulínico) e 68 (ácido platânico), isolados do extrato metanólico das folhas de Zyzigium claviflorum (Roxb.) Wall (família Myrtaceae) juntamente com o lupeol (69), revelaram atividade anti-HIV (Human Immunodeficiency Virus $)$, o mesmo ocorrendo com os derivados $(\mathbf{6 7 b}-\mathbf{6 7 h})$ obtidos por transformações químicas de $\mathbf{6 7 . 3 6}$

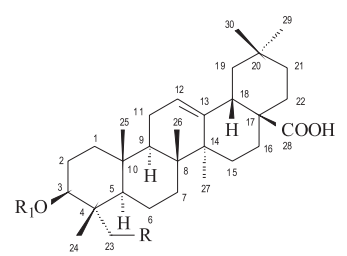

$62 \mathrm{R}=\mathrm{CH}_{2} \mathrm{OH}$

$R_{1}=\alpha$-L-ramnopiranosil- $(1 \rightarrow 2)-\alpha$-L-arabinopiranosi

$63 \mathrm{R}=\mathrm{CH}_{3}$

$R_{1}=\beta-D$-glicopiranosil- $(1 \rightarrow 4), \alpha$-L-ramnopiranosil-(1 $\left.\rightarrow 2\right)$ - $\alpha$-L-arabinopiranosi

$64 \mathrm{R}=\mathrm{CH}_{3}$

$\mathrm{R}_{1}=\beta$-D-glicopiranosil-(1 $\left.\rightarrow 3\right)$ - $\alpha$-L-ramnopiranosil-(1 $\left.\rightarrow 2\right), \beta$-D-glicopiranosil $(1 \rightarrow 4)-\alpha$-Larabinopiranosil

$65 \mathrm{R}=\mathrm{CH}_{2} \mathrm{OH}$

$R_{1}=\beta-D$-glicopiranosil- $(1 \rightarrow 2)-\beta-D$-glicopiranosil- $(1 \rightarrow 4)-\beta-D$-glicopiranosil- $(1 \rightarrow 3)-\alpha-L$ ramnopiranosil-(1 $\rightarrow 2), \beta$-D-glicopiranosil $(1 \rightarrow 3)-\beta-D$-glicopiranosil- $(1 \rightarrow 4)-\alpha-L-$ arabinopiranosil

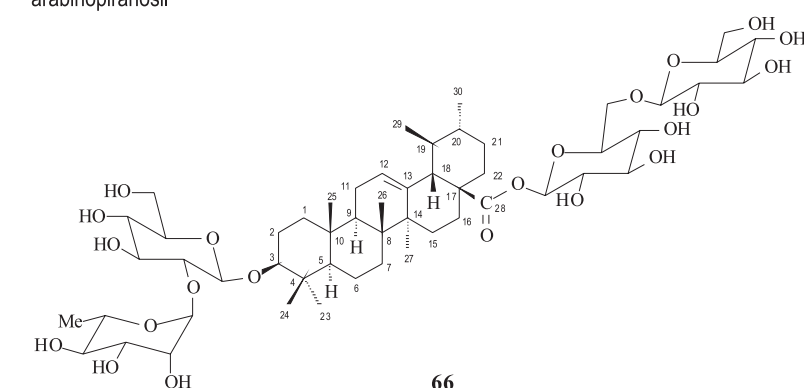

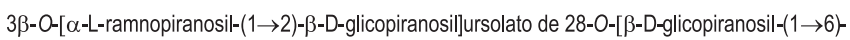
$\beta$-D-glicopiranosila

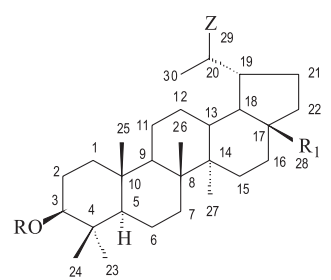

$\mathbf{R}$

$\begin{array}{llll} & \mathrm{R}_{1} & \mathbf{Z} & \\ 67 & \mathrm{H} & \mathrm{COOH} & =\mathrm{CH}_{2} \\ 67 \mathrm{a} & \mathrm{H} & \mathrm{CH}_{2} \mathrm{OH} & =\mathrm{CH}_{2} \\ 67 \mathrm{~b} & \mathrm{H} & \mathrm{CO}_{2} \mathrm{CH}_{2} \mathrm{CO}_{2} \mathrm{CH}_{3} & =\mathrm{CH}_{2} \\ 67 \mathrm{c} & \mathrm{COCH}_{3} & \mathrm{COOH} & =\mathrm{CH}_{2} \\ 67 \mathrm{~d} & \mathrm{COC}_{6} \mathrm{H}_{5} & \mathrm{COOH} & =\mathrm{CH}_{2} \\ 67 \mathrm{e} & \mathrm{COCH}_{2} \mathrm{CHCH}_{3} & \mathrm{COOH} & =\mathrm{CH}_{2} \\ 67 \mathrm{f} & \mathrm{SO}_{2} \mathrm{~K} & \mathrm{COOH} & =\mathrm{CH}_{2} \\ 67 \mathrm{~g} & \mathrm{COCH} \mathrm{CH}_{2} \mathrm{CO}_{3} \mathrm{H} & \mathrm{COOH} & =\mathrm{CH}_{2} \\ 67 \mathrm{~h} & \mathrm{H} & \mathrm{COOH} & \mathrm{CH}_{3} \\ 68 & \mathrm{H} & \mathrm{COOH} & 0 \\ 69 & \mathrm{H} & \mathrm{CH} & =\mathrm{CH}_{2}\end{array}$

A investigação da atividade inibitória destas substâncias na replicação de HIV em linfócitos H9 permitiu aos autores da referência 36 as seguintes deduções:

a) o derivado ácido 20,29-di-hidrobetulínico (67h) revelou-se mais potente do que 67 e 68 (29-nor-triterpenoide), demonstrando que o tipo de substituinte presente no átomo de carbono C-19 (67 com grupo isopropenila, 68 com acetila e $67 \mathbf{h}$ com isopropil) assume importância na atividade anti-HIV;

b) a substituição do grupo carboxila de carbono $\mathrm{C}-17$ por $-\mathrm{CH}_{2} \mathrm{OH}$ (67a, betulina) ou a conversão em grupamento éster por reação de esterificação (67b) diminui a atividade anti-HIV;

c) a esterificação do grupo hidroxila localizada no carbono C-3 (67c - 67g) produziu redução na ação anti-HIV, revelando que a presença desta função hidroxila é essencial para o desempenho da atividade como agente anti-AIDS. ${ }^{36}$

A importância do ácido betulínico (67) estimulou o desenvolvimento 
de novas atividades de pesquisa na busca, inclusive, de produtos derivados dotados de outras atividades biológicas através de biotransformações químicas ${ }^{37}$ ou utilizando, inclusive, novos reagentes e novas reações. ${ }^{38-41}$

Transformações microbiológicas (biotransformações, Esquema 6) para obtenção de substâncias mais ativas e/ou menos tóxicas assumem interesse social e econômico, principalmente quando tais conversões seletivas através de modificações sintéticas revelam dificuldades (Esquema 6). ${ }^{37}$

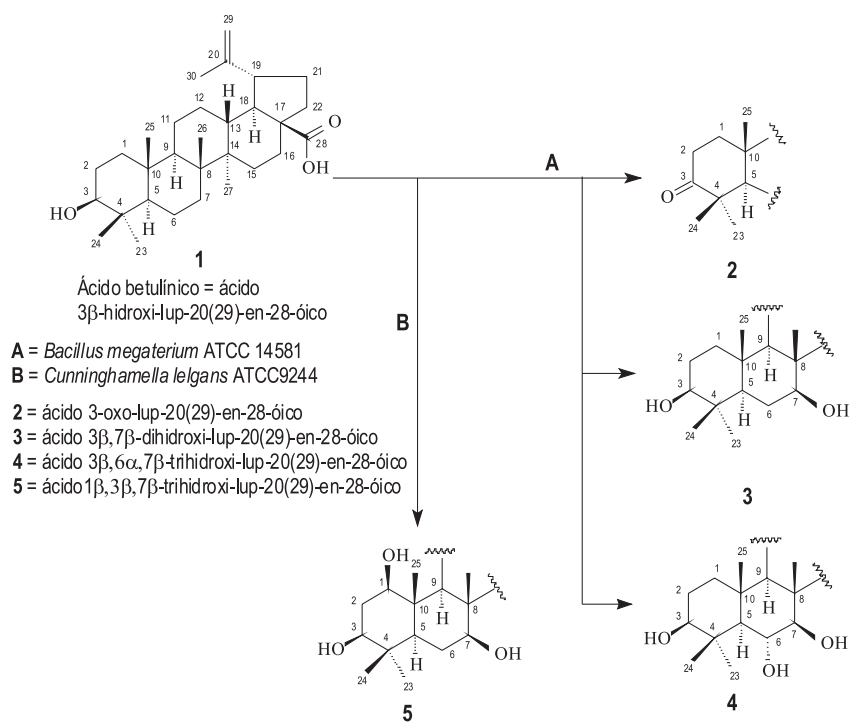

Esquema 6. Biotransformações do ácido betulínico ${ }^{37}$

As transformações microbiológicas de substâncias naturais e sintéticas oferecem novos horizontes para modificações estruturais destinadas a vários objetivos, desde a introdução de grupos funcionais a rearranjos moleculares.

Quatro exemplos adicionais de transformações sintéticas foram descritos em publicações recentes (todas de 2009) e autoexplicativas pelos títulos dos artigos em inglês: Enhancing the Divergent Activities of Betulinic Acid via Neoglycosylation, ${ }^{38}$ Synthesis and Cytotoxicity of Bidesmosdic Betulin and Betulinic Acid Saponins, ${ }^{39}$ Synthesis of betulinic acid acyl glucuronide for application in anticancer prodrug monotherapy, ${ }^{40}$ Synthesis, cytotoxicity, and germanicane-type rearrangement products. ${ }^{41}$

Outras classes de substâncias naturais têm também revelado potente atividade inibidora sobre HIV, podendo-se citar, como exemplos adicionais, a cumarina $\mathbf{7 0}^{42,43} \mathrm{e}$ os flavonoides $7-O-\beta$-D-galactopiranosilacacetina (71) e crisina (72), isolados das flores de Chrysantbermum morifolium (família Compositae) juntamente com mais sete substâncias conhecidas, sendo que a conhecida flavona crisina (72) revelou-se a mais ativa. ${ }^{44}$<smiles>CCCc1cc(=O)oc2c3c(c4c(c12)OC(C)(C)C=C4)OC(C)C(C)C3O</smiles>

70

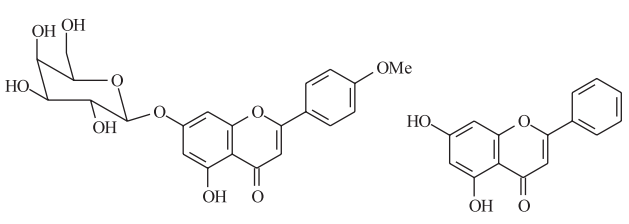

71
Nacional de Câncer dos USA assumiu a coordenação de programa destinado à obtenção desta substância orgânica natural e de outras incluídas no mesmo objetivo ou interesse correlacionado.

O baixo rendimento $(\sim 0,02 \%)$ fornecido pela espécie vegetal Taxus brvifolia, família Taxaceae, inviabilizou o atendimento da demanda normal para suprir as exigências de saúde do próprio país. Entre as tentativas para superação deste problema destaca-se a investigação de outras espécies do mesmo gênero Taxus, a preparação de produto semi-sintético utilizando como matéria-prima taxoides apropriados e mais abundantes, a cultura de células (fonte renovável) e a síntese total.

Duas rotas de síntese total do taxol (Scripps Research lnstitute, La Jolla University of California, San Diego e Florida State University, Tallahassee) encontram-se descritas na literatura. ${ }^{45}$

Cultura de células do tecido do caule de Taxus baccata produziu quatro novos taxoides (73 - 76) com atividade semelhante à desempenhada pelo taxol $(\mathbf{6}) .{ }^{46}$ Os baixos rendimentos obtidos devem servir como estímulo adicional para a continuação do desenvolvimento desta linha de atividade de investigação químico-biológica, que assume grande importância pela contribuição na preservação da vida, na cura de doenças, na manutenção e compreensão dos fenômenos que comandam a natureza, além do desenvolvimento socioeconômico como consequência.
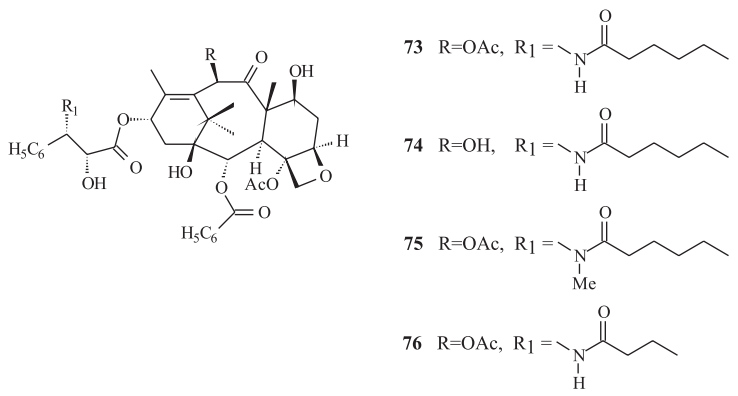

A lactona macrocíclica lasiodiplodina (77), substância natural isolada de Euphorbia splendus (família Euphorbiaceae), revelou potente atividade antileucêmica. ${ }^{47}$ Esta substância foi também isolada em pequena quantidade de Annona dioica, (família Anonaceae), sendo que a possibilidade enantiomérica (o carbono 14 é quiral e permite dois estereoisômeros) ainda não foi definitivamente estabelecida. ${ }^{48}$

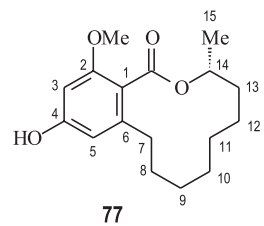

Entre os medicamentos antitumorais de origem vegetal, destacamse os derivados e os correspondentes produtos naturais bioproduzidos pelas espécies Catharanthus roseus ou Vinca rósea, família Apocynaceae (9 e 10, e seus derivados 78 e 79), Camptotheca acumata, família Nyssaceae ( $\mathbf{8 0}$ e seu derivados $\mathbf{8 1}$ e 82) e Podophyllum peltatum e $P$. emodi, família Berberidaceae (11 e 12, derivados de 13). ${ }^{49}$

Estas nove substâncias naturais $(\mathbf{9}, \mathbf{1 0}, 13$ e 80) e seus derivados $(11,12,78,79$ e 81e 82) atuam em diferentes tipos de câncer, revelando espectro de atividade e toxicidade diferentes, ampliando a utilidade medicinal em benefício da saúde.

O Brasil conta, atualmente, com grupos de pesquisa empenhados em investigações de substâncias naturais anticancerígenas e outras atividades biológicas, podendo-se citar como exemplos alguns resultados publicados em periódicos científicos de circulação internacional. A naftoquinona $\mathbf{8 3}$, denominada lipsidoquinona, para tratamento do câncer de mama, promoveu intensas investigações para a obtenção desta substância natural e seus derivados. O Instituto

\section{SUBSTÂNCIAS ORGÂNICAS NATURAIS E SEMISSINTÈTICAS ANTICANCER}

A grande demanda por taxol (6) nos Estados Unidos, utilizado 


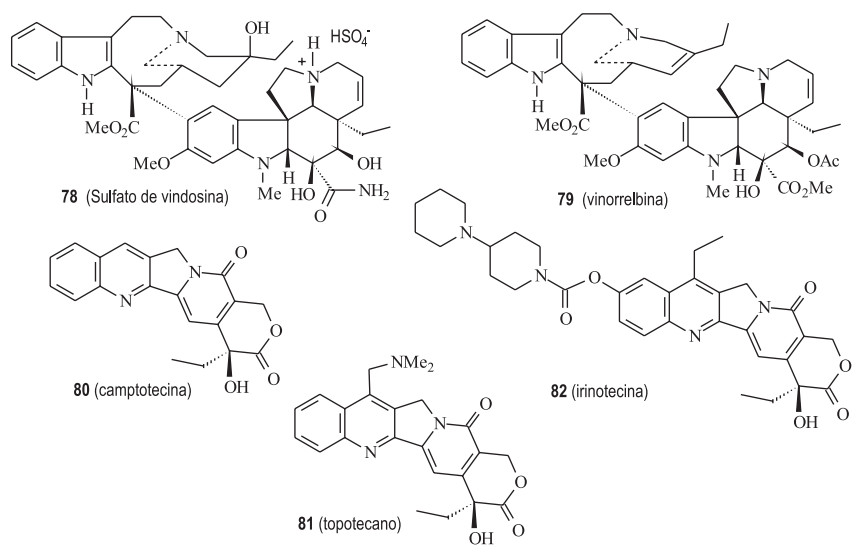

isolada de Lippia sidoides (família Verbenaceae), ${ }^{50}$ o flavonoide 84, denominada diploflavona, isolada de Diplotropis ferruinea, família Fabaceae, ${ }^{51}$ biflavonoides $\mathbf{8 5}$ e 86, isolados das espécies Ouratea hexasperma e Ouratea semiserrata, respectivamente, família Ochnaceae, ${ }^{52}$ as witafisalinas $\mathbf{8 7}$ (witafisalina $\mathrm{M}$ ), $\mathbf{8 8}$ (witafisalina N) e $\mathbf{8 9}$ (witafisalina $\mathrm{O}$ ) isoladas das folhas de Acnistus arborescens, família Solonaceae., ${ }^{53,54}$ As investigações biológicas destas witafisalinas M, $\mathrm{N}$ e $\mathrm{O}$ revelaram atividades tripanocída ${ }^{55}$ e citostática seletiva ${ }^{56} \mathrm{com}$ resultados expressivos e promissores.

Seria inoportuno concluir este tópico sumário sobre plantas anticancerígenas sem citar duas publicações de grande relevância, uma de avaliação perspectiva ${ }^{57}$ e outra de revisão: ${ }^{58}$ Cragg e Newman, Plants as a source of anti-cancer agents, ${ }^{57}$ Nobili e coautores, Natural compounds for câncer treatment and preventi. ${ }^{58}$

Os títulos de tais publicações são autoexplicativos e podem ser considerados como suficientemente claros para o entendimento do leitor, o mesmo ocorrendo com dois dos três artigos abaixo descritos.

Para demonstrar que estamos distantes da possibilidade de esgotar a importância das substâncias naturais, apontando sinalização para novas perspectivas, destaco ainda: Fawole e coautores, Anti-inflammatory and phytochemical properties of twelve medicnal plants used for
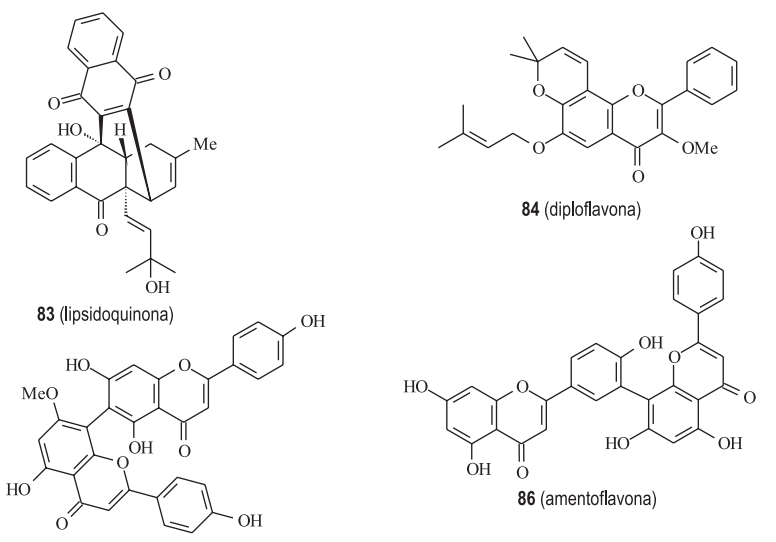

85 (O-metilagatisflavona)

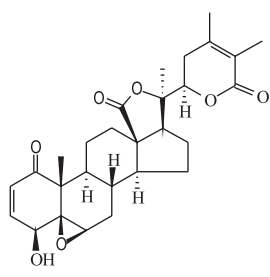

87 (witafisalina M)

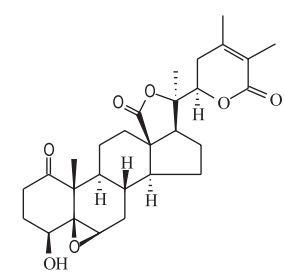

88 (witafisalina $\mathrm{N}$ )

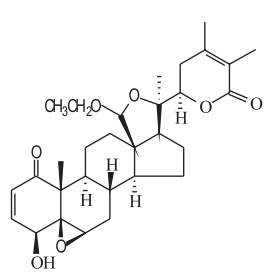

89 (witafisalina 0) treatment gastro-intestinal ailments in South África, ${ }^{59}$ Powell, Plant Seeds as Source of Potential Industrial Chemicals, Pharmaceuticals, and Pest Control Agents, ${ }^{60}$ Danelli e coautores, Leishmanicidal effect of LLD-3 (90), a nor-triterpene isolated from Lophanthera lactescens. ${ }^{61}$

Esta última publicação trata da investigação biológica de um nor-triterpeno (90) isolado de Lophanthera lactescens, família Malpighiaceae, a principal substância natural da dissertação de mestrado (Título: Constitutintes Químicos da Espécie Lophanthera lactescens) de um dos autores (H. dos S. A.), defendida em 1985, UFRRJ). Esta substância marcou um início importante da utilização de técnicas 2D de RMN $\left[{ }^{1} \mathrm{H}-{ }^{1} \mathrm{H}-\mathrm{COSY},{ }^{1} \mathrm{H}-{ }^{1} \mathrm{H}-\mathrm{NOESY},{ }^{1} \mathrm{H}-{ }^{13}-\mathrm{COSY}-{ }^{n} \mathrm{~J}_{\mathrm{CH}}\right.$ (n=2 e 3) e INADEQUATE] no Brasil, aproveitando uma viagem do Shoolery (importante profissional do NMR Applications Laboratory Varian Associates, Palo Alto, Califórnia, USA) ao nosso País. A utilização de tais técnicas permitiu completar a elucidação estrutural deste nor-triterpeno $(\mathbf{9 0}){ }^{62}$

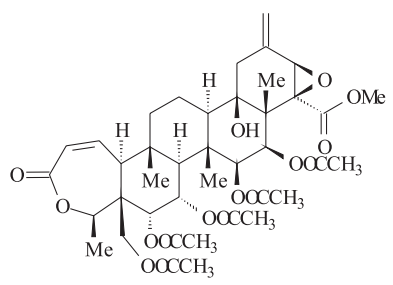

90

O sucesso estrutural desta substância gerou uma expressiva procura para avaliação de atividade biológica, produzindo resultados estimuladores. Infelizmente, quando acordamos e despertamos para entendimento da grande procura não tínhamos mais proteção sobre a própria substância, restando como possibilidade alternativa somente o direito de patentear o processo de isolamento e, consequentemente, nenhum benefício das patentes resumidas na Tabela 3 .

Para concluir, esperamos que os exemplos acima citados, representativos de aplicações farmacológicos de substâncias orgânicas naturais produzidas pelo metabolismo secundário possam contribuir para: 1. demonstrar, de forma inequívoca, a importância atual das atividades de isolamento e elucidação estrutural das substâncias produzidas pelo metabolismo secundário (especializado) dos organismos vivos. Parece-me oportuno transcrever uma frase da conclusão do artigo de Nobili e coautores: ${ }^{58}$ "The identification and development of natural compounds and their derivatives have greatly contributed to this progress and many of these compounds are now being used in clinical practice." Este depoimento aparece após comentário sobre o progresso de tratamento médico como resultado das pesquisas desenvolvidas para descoberta de novos medicamentos antitumor. 2. Como mais uma advertência para a preservação dos organismos vegetais, laboratórios vivos de quimismo, que podem ser explorados racionalmente.

A descoberta de novas estruturas e a catalogação de substâncias fabricadas pelos organismos vivos devem ser ampliadas com investigações farmacológicas, ecológicas, produtivas (inclusive com culturas de células e tecidos), genéticas, fisiológicas, alimentícias e biossintéticas, estendendo-se a outras áreas da biologia e da química. A bioprodução de substâncias com estereoquímicas definidas e a introdução e modificação seletivas de grupos funcionais em substratos naturais ou sintéticos dependem do conhecimento detalhado das rotas biogenéticas.

A literatura tem registrado com frequência, nos últimos anos, metodologias destinadas ao isolamento de substâncias com atividade biológica específica. A adoção desse procedimento imediatista é 
Tabela 3. Patente on line envolvendo a substância natural 90, isolada de Lophanthera lactescens, família Malpighiaceae

\begin{tabular}{lcclc}
\hline Patent & Pub.Date & Inventor & Assignee & Title \\
\hline US6100293 & $2000-08-08$ & Baker; Robert K. & Merck \& Co., Inc. & Tetracyclic triterpene derivatives with immunosuppressant activity \\
US6083980 & $2000-07-04$ & Baker; Robert K. & Merck \& Co., Inc. & Furanyl, tetracyclic triterpene derivatives with immunosuppressant activity \\
US6051590 & $2000-04-18$ & Bao; Jianming & Merck \& Co., Inc. & Immunosuppressant tricyclic compounds \\
US6022890 & $2000-02-08$ & Bao; Jianming & Merck \& Co., Inc. & Immunosuppressant tetracyclic triterpenes \\
US5998408 & $1999-12-07$ & Baker; Robert K. & Merck \& Co., Inc. & Triterpene derivatives with immunosuppressant activity \\
US5952371 & $1999-09-14$ & Baker; Robert K. & Merck \& Co., Inc. & Triterpene derivatives with immunosuppressant activity \\
US5883119 & $1999-03-16$ & Baker; Robert K. & Merck \& Co., Inc. & Triterpene derivatives with immunosuppressant activity \\
US5874594 & $1999-02-23$ & Baker; Robert K. & Merck \& Co., Inc. & Triterpene derivatives with immunosuppressant activity \\
US5763478 & $1998-06-09$ & Baker; Robert K. & Merck \& Co., Inc. & Triterpene derivatives with immunosuppressant activity \\
US5696156 & $1997-12-09$ & Baker; Robert K. & Merck \& Co. Inc. & Triterpene derivatives with immunosuppressant activity \\
US5679705 & $1997-10-21$ & Baker; Robert K. & Merck \& Co., Inc. & Triterpene derivatives with immunosuppressant activity \\
\hline
\end{tabular}

Fonte: http://www.freepatentsonline.com/5998408.html

prática e útil, mas estimula a possibilidade de desprezar, em alguns casos, precursores inativos presentes em maior porcentagem, os quais podem ser transformados no produto ativo com alto rendimento, por simples reações de laboratório. Aliás, a inatividade revelada por substância da mesma classe daquela ativa pode fornecer informação sobre a sua natureza química, essencial para o desempenho da atividade biológica. Além disso, a possibilidade de aparecimento de novas doenças e a descoberta de novos ensaios farmacológicos mais eficientes e específicos não podem ser ignoradas.

Obviamente, outras disciplinas e atividades de pesquisa baseadas no quimismo dos organismos vivos (sistemática, evolução e ecologia químicas) também podem ser prejudicadas por dados fito-químicos incompletos; a pressa e as considerações "práticas" não devem inibir o rigor científico.

\section{AGRADECIMENTOS}

Registro meus agradecimentos ao Conselho Nacional de Desenvolvimento Científico e Tecnológico (CNPq, onde atuei como Membro do Comitê de Química durante três mandatos) pelos auxílios, Bolsas de Apoio Técnico e Bolsa de Produtividade em Pesquisa (Pesquisador 1A de 1976 a março de 2003 e Pesquisador Sênior desde fevereiro de 2003); à Coordenação de Aperfeiçoamento de Pessoal de Nível Superior (CAPES) pela concessão especial como Membro de Comitê de avaliação e como representante; à Fundação de Amparo à Pesquisa do Estado do Rio de Janeiro (FAPERJ, onde ocupei a Coordenação da área de Química, Ciências Exatas e Ciências da Terra durante dois períodos) pelos auxílios, Bolsas Cientista do Nosso Estado e a atual Bolsa de Pesquisador Visitante Emérito/UENF/UFRRJ desde agosto de 2008; a todos pesquisadores e técnicos colaboradores de diversas universidades públicas brasileiras, alunos de graduação (Bolsistas de Iniciação Científica e estagiários) e de Pós-graduação (Mestrado e Doutorado, oferecidos por Programas de Pós-graduação de universidades brasileiras) e à minha esposa e filhos pela constante compreensão, felicidade e carinho.

\section{REFERÊNCIAS}

1. Torssell, K. B. G;. Natural Product Chemistry: A mechanistic, biosynthetic and ecological approach ( $2^{\text {nd }}$ ed.), Apotekarsocieteten-Swedish Pharmaceutical Society: Stockholm, 1997.

2. Dewick, P. M.; Medicinal Natural Products: A Biosynthetic Approach ( $2^{\text {nd }}$ ed.), John Wiley: New York, 2001.
3. Cordell, C. E.; Farnsworth, N. R.; Beecher, C. W. W.; Soejarto, D. D.; Kinghorn, A. D.; Pezzuto, J. M.; Wall, M. E.; Wani, M. C.; Brown, D. M.; O’Neill, M. J.; Lewis, J. A.; Tait, R. M.; Harris, T. J. R. Em Human Medicinal Agents from Plants; Kinghorn, A. D.; Balandrin, M. F., eds.; American Chemical Society-ACS Symposium Series 534: Washington - DC., 1993, p. 191-204.

4. Cragg, G. M.; Boyd, M. R.; Cardellina II, J. H.; Grever, M. R.; Schepartz, S. A.; Snader, K. M.; Suufness, M. Em ref. 3, p. 80-95.

5 Buckingham, J., ed.; Dictionary of Natural Products, Chapman and Hall: London, 1993.

6. Centry, A. H. Em ref. 3, p. 13-24.

7. Braz-Filho, R; Quim. Nova 1994, 17, 405.

8. Braz-Filho, R.;. Rev. de Medicina da UFC 1994, 34, 38.

9. Braz-Filho, R.; Pure Appl. Chem. 1999, 71, 1663.

10. Vieira, I. J. C.; Braz-Filho, R. Em Natural Product Chemistry - Bioactive Natural Products; Atta-ur-Rahman, ed.; Elsevier Science Publishers: The Netherlands, 2005, vol. 33, p. 433-492.

11. Lemos, T. L. G.; Monte, F. J. Q.; dos Santos, A. K. L.; Fonseca, A. M.; Santos, H. S.; Oliveira, M. F.; Costa, S. M. O., Pessoa, O. D. L.; BrazFilho, R.; Nat. Prod. Res. 2007, 21, 529.

12. Cragg, G. M.; Newman, D. J.; Snades, K. M.; J. Nat. Prod. 1997, 60, 52.

13. Newman, D. J.; Cragg, G. M.; Snades, K. M.; J. Nat. Prod. 2003, 66, 1022.

14. de Morais, S. M.; Braz-Filho, R., orgs.; Produtos Naturais: Estudos Químicos e Biológicos, Ed. da Universidade Estadual do Ceará: Fortaleza, 2007.

15. Centry, A. H. Em ref. 3, p. 13-24.

16. Klaynnn, D. L. Em ref. 3, p. 242-255.

17. Nair, M. S. R.; Basile, D. V.; J. Nat. Prod. 1993, 56, 1559.

18. Brandão, M. G. L.; Carvalho, L. H.; Kretti, A. U.; Ciência Hoje 1991, 18,9 .

19. Kumar, V.; Mahajan, A.; Chibale, K.; Bioorg. Med. Chem. 2009, 17, 2236.

20. Kaur, K.; Jain, M.; Kaur, T.; Jain, R.; Bioorg. Med. Chem. 2009, no prelo.

21. Vieira, I. J. C.; Braz-Filho, R.; Rodrigues-Filho, E.; Vieira, P. C.; da Silva, M. F. G. F.; Fernandes, J. B.; J. Braz. Chem. Soc. 1999, 10, 76.

22. de Sousa, R. P.; Barbosa, L. F.; de Oliveira, A. F.; Mathias, L.; BrazFilho, R.; Vieira, I. J. C.; Nat. Prod. Res. 2005, 19, 151.

23. Maillard, M.; Marston, A.; Hostettmann,. K. Em Humman Medicinal Agents from Plants; Kinghorn, A. D.; Balandrin, M. F., eds.; American Chemical Society - ACS Symposium Series $N^{\circ}$ 534, Washington-DC, 1995, p. 256-273. 
24. Lemos, T. L. G.; Mendes, A. L.; Sousa, M. P.; Braz-Filho,. R; Fitoterapia 1992; 53, 515.

25. Domon, B.; Hostettmann, K.; Helv. Chim. Acta 1986, 69, 2038.

26. Dzubak, P.; Hajduch, M.; Vydra, D.; Hustova, A.; Kvasnica, M.; Biedermann, D.; Markova, L.; Urban, M.; Sarck, J.; Nat. Prod. Rep. 2006, 23, 394.

27. Sparg, S. G.; Light, M. E.; van Studen, J.; J. Ethnopharmacol. 2004, 94, 219.

28. Sha, Y.; Yan, M.-C.; Liu, J.; Liu, Y.; Cheng, M.-S.; Molecules 2008, 13, 1472.

29. Huang, X.; Cheng, S.; Du, Y.; Bing, F.; Carbohydr. Res. 2009, no prelo.

30. Silva, T. M. S.; Câmara, C. A.; Agra, M. de F.; de Carvalho, M. G.; Frana, M. T.; Brandoline, S. S. P. B.; Paschoal, L. da S.; Braz-Filho, R.; Fitoterapia 2006, 77, 449.

31. Silva, T. M. S.; Braz-Filho, R.; de Carvalho, M. G.; Agra, M. de F.; Biochem. Syst. Ecol. 2002, 30, 1083.

32. Esteves-Souza, A.; Silva, T. M. S.; Alves, C. C. F.; de Carvalho, M. G.; Braz-Filho, R.; Echevarria, A.; J. Braz.. Chem. Soc. 2002, 13, 838.

33. Santiago, G. M. P.; Viana, F. A.; Pessoa, O. D. L.; Santos, R. P.; Pouliqyuen, Y. B. M.; Arriaga, A. M. C.; Andrade-Neto, M.; Braz-Filho, R.; Rev. Bras. Farmacognosia 2005, 15, 187.

34. Chun, J.; Goodman, C. L.; Rice, W. C.; Mcinthosi, A. H.; Chippendale, G. M.; Schubert, K. R.; J. Econ. Entomol. 1994, 87, 1754.

35. Diniz, L. R. L.; Santana, P. C.; Ribeiro, A. P. A. F.; Portella, V. G.; Pachec, L. F.; Meyer, N. B.; César, I. C.; Consenza, G. P.; Brandão, M. das G. L.; Vieira, M. A. R.; J. Ethnopharm. 2009, 123, 275.

36. Fugioka, T.; Kashiwada, Y.; Kilkuskie, R. E.; Cosentino, L, M.; Ballas, L. M.; Jiang, J. B.; Janzen, W. P.; Chen, I. S.; Lee, K. H.; J. Nat. Prod. 1994, 57, 243.

37. Samir, A; Chatterjee, K. P.; Pezzuto, J. M.; Hamann; M. T.; J. Nat. Prod. 2000, 63, 1653.

38. Goff, R. D.; Thorson, J. S.; Org. Lett. 2009, 11, 461.

39. Gauthier, C.; Legault, J.; Lavoie, S.; Rondeau, S.; Tremblay, S.; Pichette, A.; J. Nat. Prod. 2009, 72, 72.

40. Gauthier, C.; Legault, J.; Lavoie, S.; Rondeau, S.; Pichette, A.; Tetrahedron Lett. 2009, 50, 988.

41. Gauthier, C.; Legault, J.; Piochon, M.; Lavoie, S.; Tremblay, S.; Pichette, A.; Bioorg. Med. Chem. Lett. 2009, 19, 2310.

42. Cardellina II, J. H.; Gustafson, K. R.; Beutler, J. A.; McKee, T. C..; Hallock, Y. F.; Fuller, R. W.; Boyd. M. R. Em ref. 3, p. 218-227.

43. Clark A. M.; Hufford.: C. D. Em ref. 3, p. 225-241.

44. Hu, C.-Q,; Chem, K.; Shi, Q.; Kilkuskie, R. E.; Cheng, Y.-C.; Lee, K.H.; J. Nat. Prod. 1994, 57, 42.
45. Borman, S.; Chem. Eng. News 1994, 72, 32.

46. Ma, W.; Park, G. L.; Gomez, G. A.; Nieder, M. H.; Adams, T. L.; Aynsley, J. S.; Sahai, O. P.; Smith, R. J.; Stahlhut, R. W; Hylands, P. J.; Bitsch, F.; Shackleton., C.; J. Nat. Prod. 1994, 57, 116.

47. Lee, K. H.; Hayashi, N.; Okano, M.; Hiall, I. H.; Wu, R. Y.; McPhail, A. T.; Phytochemistry 1982, 21, 1119.

48. dos Santos, P. R. D.; Morais, A. A.; Braz-Filho, R.; J. Braz.. Chem. Soc. 2003, 14, 396.

49. Mariana, L. de M.; Tese de Doutorado, Universidade de Brasília, Brasil, 2009, p. 31-47.

50. Costa, S. M. O.; Lemos, T. L. G.; Pessoa, O. D. L.; Pessoa, C.; Montenegro, R. C.; Braz-Filho, R.; J. Nat. Prod. 2001, 64, 792.

51. Almeida, J. R. G. S.; Barbosa-Filho, J. M.; Cabral, A. G. S.; Agra, M. de F.; da Cunha, E. V. L.; da Silva, M. S.; do Nascimento, S. C.; Braz-Filho, R.; J. Braz.. Chem. Soc. 2005, 6B, 1454.

52. de Carvalho, M. G.; Velandia, J. R.; de Oliveira, M. C. C.; Echevarria, A.; Braz-Filho, R.; Grynberg, N.; Recent Progress in Medicinal Plants - Phytochemistry \& Pharmacology II 2002, 8, 77.

53. Veras, M. L..; Bezerra, M. Z. B.; Lemos, T. L. G.; Uchoa, D. E de A.; Braz-Filho, R.; Chai, H.-B.; Cordell, G. A.; Pessoa, O. D. L.; J. Nat. Prod. 2004, 67, 710.

54. Veras, M. L.; Bezerra, M. Z. B.; Braz-Filho, R.; Pessoa, O. D. L.; Montenegro, R. C.; Pessoa, C. de O.; de Moraes, M. O.; Costa-Lotufo, L. V.; Planta Medica 2004, 70, 551.

55. Vieira, N. C.; Espindola, L. S.; Santana, J. M.; Veras, M. L.; Pessoa, O. D. L.; Pinheiro, S. M.; de Araújo, R. M..; Lima, M. A. S.; Silveira, E. R.; Bioorg. Med. Chem. 2008, 16, 1676.

56. Rocha, D. D.; Militão,G. C. G.; Veras, M. L.; Pessoa, O. D. L.; Silveira, E. R.; Alves, A. P. N. N.; de Moraes, M. O.; Pessoa, C.; Costa-Lotufo, L. V.; Life Sci. 2006, 79, 1692.

57. Cragg, G. M.; Newman, D. J.; J. Ethnopharmacol. 2005, 100, 72.

58. Nobili, S.; Lippi, D.; Witort, E.; Donnini, M.; Bausi, L.; Mini, E.; Capaccioli, S.; Pharm. Res. 2009, 59, 365.

59. Fawole, O. A. A.; Ndhlala, R.; Amoo, S. O.; Finne, J. F.; Van Standen, J.; J. Ethnopharmacol. 2009, 123, 237.

60. Powell, R. G.; J. Nat. Prod., no prelo.

61. Danelli, M. G. M.; Soares, D. C.; Abreu, ,H. S.; Peçanha, L. M. T.; Saraiva, E. M.; Phytochemistry 2009, 70, 608.

62. Abreu, H. dos S.; Braz-Filho, R.; Gottlieb, H. E.; Sholery, J. N.; Phytochemistry 1990, 29, 2257. 